\title{
Soft Stylus Probes for Scanning Electrochemical Microscopy
}

\author{
Fernando Cortés-Salazar, ${ }^{\dagger}$ Markus Träuble, ${ }^{\ddagger}$ Fei Li, ${ }^{\dagger}$ Jean-Marc Busnel, ${ }^{\dagger}$ Anne-Laure Gassner, ${ }^{\dagger}$ \\ Mohamad Hojeij, ${ }^{\dagger}$ Gunther Wittstock, ${ }^{\ddagger}$ and Hubert H. Girault*,†
}

\begin{abstract}
Laboratoire d'Electrochimie Physique et Analytique, Ecole Polytechnique Fédérale de Lausanne, Station 6, CH-1015 Lausanne, Switzerland, and Department of Pure and Applied Chemistry, Center of Interface Science (CIS), Faculty of Mathematics and Natural Sciences, Carl von Ossietzky University of Oldenburg,

D-26111 Oldenburg, Germany
\end{abstract}

A soft stylus microelectrode probe has been developed to carry out scanning electrochemical microscopy (SECM) of rough, tilted, and large substrates in contact mode. It is fabricated by first ablating a microchannel in a polyethylene terephthalate thin film and filling it with a conductive carbon ink. After curing the carbon track and lamination with a polymer film, the V-shaped stylus was cut thereby forming a probe, with the cross section of the carbon track at the tip being exposed either by UVphotoablation machining or by blade cutting followed by polishing to produce a crescent moon-shaped carbon microelectrode. The probe properties have been assessed by cyclic voltammetry, approach curves, and line scans over electrochemically active and inactive substrates of different roughness. The influence of probe bending on contact mode imaging was then characterized using simple patterns. Boundary element method simulations were employed to rationalize the distance-dependent electrochemical response of the soft stylus probes.

Scanning electrochemical microscopy (SECM) is a scanning probe technique that provides spatially resolved detection of electrochemical and chemical surface reactivity. ${ }^{1,2}$ Typically, the probe is an amperometric disk-shaped ultramicroelectrode (UME) enclosed in an insulating sheath, e.g. glass. Due to the hemispherical diffusion occurring at the microdisc electrode, a steadystate current can be monitored as a function of the horizontal $(x, y)$ and vertical $(z)$ probe positions. SECM has found many applications ranging from surface reactivity imaging ${ }^{3-13}$ to the

* To whom correspondence should be addressed. E-mail: hubert.girault@ epfl.ch. Telephone: +41-21-693 3145. Fax: +41-21-693 3667.

$\dagger$ Ecole Polytechnique Fédérale de Lausanne.

‡ Carl von Ossietzky University of Oldenburg.

(1) Bard, A. J., Mirkin, M. V., Eds. Scanning electrochemical microscopy; John Wiley and Sons: New York, 2001.

(2) Kwak, J.; Bard, A. J. Anal. Chem. 1989, 61, 1221-1227.

(3) Bard, A. J.; Fan, F. R. F.; Pierce, D. T.; Unwin, P. R.; Wipf, D. O.; Zhou, F. Science 1991, 254, 68-74.

(4) Casillas, N.; Charlebois, S. J.; Smyrl, W. H. J. Electrochem. Soc. 1993, 140.

(5) Sun, P.; Laforge, F. O.; Mirkin, M. V. Phys. Chem. Chem. Phys. 2007, 9, 802-823.

(6) Wittstock, G.; Burchardt, M.; Kirchner, C. N. In Electrochemical Sensor Analysis; Alegret, S., Merkoçi, A., Eds.; Elsevier: Amsterdam, The Netherlands, 2007; Vol. 49, pp 907-939.

(7) Wittstock, G.; Burchardt, M.; Pust, S. E.; Shen, Y.; Zhao, C. Angew. Chem., Int. Ed. 2007, 46, 1584-1617. study of the kinetics of homogeneous and heterogeneous reactions at solid/liquid, gas/liquid, and liquid/liquid interfaces. ${ }^{14-20} \mathrm{Be}-$ cause the response of a SECM probe can be described by continuum models of mass transport coupled to electrochemical kinetics, quantitative kinetic information can be extracted by comparing experimental and simulated curves in many practically relevant situations. ${ }^{21-25}$

The response of a SECM probe depends on the surface reactivity of the sample and the distance $d$ between the surface and the active area of the probe electrode. In order to obtain a reactivity image that is not influenced by topography, $d$ must be kept constant. In conventional SECM operations, this is achieved by working on samples with a roughness that is considerably smaller than the radius $r_{\mathrm{T}}$ of the UME and by leveling the plane of the sample surface with respect to the $x, y$-scanning plane of the positioning system. However, this approach becomes inappropriate on rough surfaces of large aspect ratios or when large scan areas (in the $\mathrm{mm}^{2}$ range) have to be investigated so that leveling becomes a major obstacle. Similar limitations apply when imaging curved samples.

This drawback has been recognized for a long time. In the case of a small $r_{\mathrm{T}}$, a constant $d$ can be maintained by combining

(8) Pust, S. E.; Maier, W.; Wittstock, G. Z. Phys. Chem. 2008, 222, 1463-1517.

(9) Eckhard, K.; Chen, X.; Turcu, F.; Schuhmann, W. Phys. Chem. Chem. Phys. 2006, 8, 5359-5365.

(10) Eckhard, K.; Schuhmann, W. Analyst 2008, 133, 1486-1497.

(11) Shiku, H.; Ohya, H.; Matsue, T. In Encyclopedia of Electrochemistry: Bioelectrochemistry; Bard, A. J., Stratmann, M., Eds.; Wiley: New York, 2002; Vol. 9, pp 259-275.

(12) Amemiya, S.; Guo, J.; Xiong, H.; Gross, D. A. Anal. Bioanal. Chem. 2006, $386,458-471$

(13) Ufheil, J.; Hess, C.; Borgwarth, K.; Heinze, J. Phys. Chem. Chem. Phys. 2005, 7, 3185-3190.

(14) Selzer, Y.; Turyan, I.; Mandler, D. J. Phys. Chem. B 1999, 103, 1509-1517.

(15) Bard, A. J.; Mirkin, M. V.; Unwin, P. R.; Wipf, D. O. I. Phys. Chem. 1992, 96, 1861-1868.

(16) Barker, A. L.; Gonsalves, M.; MacPherson, J. V.; Slevin, C. J.; Unwin, P. R. Anal. Chim. Acta 1999, 385, 223-240.

(17) Sun, P.; Mirkin, M. V. Anal. Chem. 2006, 78, 6526-6534.

(18) Liu, B.; Bard, A. J.; Mirkin, M. V.; Creager, S. E. L. Am. Chem. Soc. 2004, $126,1485-1492$.

(19) Mandler, D.; Unwin, P. R. J. Phys. Chem. B 2003, 107, 407-410.

(20) Lu, X.; Wang, Q.; Liu, X. Anal. Chim. Acta 2007, 601, 10-25.

(21) Wei, C.; Bard, A. J.; Mirkin, M. V. I. Phys. Chem. 1995, 99, 16033-16042.

(22) Cornut, R.; Lefrou, C. J. Electroanal. Chem. 2008, 621, 178-184.

(23) Zoski, C. G.; Mirkin, M. V. Anal. Chem. 2002, 74, 1986-1992.

(24) Selzer, Y.; Mandler, D. Electrochem. Commun. 1999, 1, 569-575.

(25) Edwards, M. A.; Martin, S.; Whitworth, A. L.; Macpherson, J. V.; Unwin, P. R. Physiol. Meas. 2006, 27, R63-R108. 
atomic force microscopy (AFM) with SECM (AFM-SECM) ${ }^{26-33}$ or by combining SECM with electrochemical tunneling microscopy (EC-STM). ${ }^{34}$ The integrated AFM-SECM probes proposed by Kranz et al. contain an insulating thorn that is used for AFM imaging and at the same time defines a constant $d$ for the frame electrode exposed by a focused ion beam..$^{28,35}$ This process has then been extended to wafer-level batch fabrication for reproducible production of standard AFM-SECM tips ${ }^{36}$ AFM-SECM probes have also been produced by attaching single-walled carbon nanotubes (SWNT) at the top of an AFM tip. ${ }^{37}$ Furthermore, metal-nanowire AFM-SECM probes have been built from SWNT by metal coating followed by insulation with a polymer film and final electrode exposition by focused ion beam (FIB).$^{38,39}$ By tilting the obtained disk-shaped probe by $11^{\circ}$, a physical contact can be established between one side of the insulating probe apex and the substrate while the active electrode area remains at a given distance from the sample. These nanowire AFM-SECM probes have been used in intermittent contact mode for high resolution imaging of both topographical and electrochemical surface information. ${ }^{39,40}$ The combined experiments are typically carried out with designated AFM or EC-STM instruments that rely on piezo positioners limiting their horizontal and, in particular, vertical scan ranges.

For rough surfaces and for sample areas larger than the typical large AFM scans (commonly maximum of $100 \mu \mathrm{m} \times 100 \mu \mathrm{m} \times 10$ $\mu \mathrm{m}$ ), a distance control has been achieved by shear-force detection in combination with a positional feedback system. ${ }^{35,41-46}$ Since the shear forces have to be measured in a viscous liquid, the signal change upon approach is rather small. Because long integration

(26) Macpherson, J. V.; Unwin, P. R. Anal. Chem. 2000, 72, 276-285.

(27) Kranz, C.; Friedbacher, G.; Mizaikofft, B.; Lugstein, A.; Smoliner, J.; Bertagnolli, E. Anal. Chem. 2001, 73, 2491-2500.

(28) Kueng, A.; Kranz, C.; Lugstein, A.; Bertagnolli, E.; Mizaikoff, B. Angew. Chem., Int. Ed. 2003, 42, 3238-3240.

(29) Sklyar, O.; Kueng, A.; Kranz, C.; Mizaikoff, B.; Lugstein, A.; Bertagnolli, E.; Wittstock, G. Anal. Chem. 2005, 77, 764-771.

(30) Davoodi, A.; Pan, J.; Leygraf, C.; Norgren, S. Electrochim. Acta 2007, 52, 7697-7705.

(31) Fasching, R. J.; Tao, Y.; Prinz, F. B. Chem. Sens. 2004, 20, 318-319.

(32) Frederix, P. L. T. M.; Bosshart, P. D.; Akiyama, T.; Chami, M.; Gullo, M. R.; Blackstock, J. J.; Dooleweerdt, K.; De Rooij, N. F.; Staufer, U.; Engel, A. Nanotechnology 2008, 19.

(33) Ueda, A.; Niwa, O.; Maruyama, K.; Shindo, Y.; Oka, K.; Suzuki, K. Angew. Chem., Int. Ed. 2007, 46, 8238-8241.

(34) Treutler, T. H.; Wittstock, G. Electrochim. Acta 2003, 48, 2923-2932.

(35) Ludwig, M.; Kranz, C.; Schuhmann, W.; Gaub, H. E. Rev. Sci. Instrum. 1995, 66, 2857-2860.

(36) Shin, H.; Hesketh, P. J.; Mizaikoff, B.; Kranz, C. Sens. Actuators, B 2008, 134, 488-495.

(37) Wilson, N. R.; Cobden, D. H.; Macpherson, J. V. I. Phys. Chem. B 2002, 106, 13102-13105.

(38) Wilson, N. R.; Macpherson, J. V. Nano Lett. 2003, 3, 1365-1369.

(39) Burt, D. P.; Wilson, N. R.; Weaver, J. M. R.; Dobson, P. S.; Macpherson, J. V. Nano Lett. 2005, 5, 639-643.

(40) Burt, D. P.; Dobson, P. S.; Weaver, J. M. R.; Wilson, N. R.; Unwin, P. R.; Macpherson, J. V. 6th IEEE Conference on SENSORS, 2007, IEEE SENSORS: Atlanta, GA, 2007; 712-715.

(41) James, P. I.; Garfias-Mesias, L. F.; Moyer, P. J.; Smyrl, W. H. J. Electrochem. Soc. 1998, 145.

(42) Lee, Y.; Ding, Z.; Bard, A. I. Anal. Chem. 2002, 74, 3634-3643.

(43) Ballesteros Katemann, B.; Schulte, A.; Schuhmann, W. Chem.-Eur.J. 2003, 9, 2025-2033.

(44) Baltes, N.; Thouin, L.; Amatore, C.; Heinze, J. Angew. Chem., Int. Ed. 2004, 43, 1431-1435.

(45) Yamada, H.; Fukumoto, H.; Yokoyama, T.; Koike, T. Anal. Chem. 2005, 77, 1785-1790.

(46) Oyamatsu, D.; Hirano, Y.; Kanaya, N.; Mase, Y.; Nishizawa, M.; Matsue, T. Bioelectrochemistry 2003, 60, 115-121. times have to be used, lateral translation rates are restricted. This becomes limiting when imaging large areas. The use of alternating current scanning electrochemical microscopy (AC-SECM) has also been proposed to circumvent these difficulties. However, the distance measurement is difficult to interpret quantitatively, since it depends on the cell setup, the nature of the sample, frequency, and electrolyte conductivity. ${ }^{47-51}$

Despite these efforts, challenges remain both for achieving higher lateral resolution and for inspection of larger sample regions. This paper addresses the latter issue encountered, for example when imaging silver-stained proteins after gel electrophoresis, ${ }^{52}$ human fingerprints, ${ }^{53,54}$ and negative photographic films. ${ }^{55}$

Here, we propose a new type of amperometric probe for SECM produced by sealing with a polymer film a carbon track microfabricated on a polyethylene terephthalate sheet. These soft stylus probes are designed to bend when pressed against a substrate such that the polyethylene terephthalate layer is always in contact upon bending. The thickness of this layer defines a constant working distance between the substrate and the active electrode area. When scanning over a rough surface, the bending of the probe can accommodate the topographic features thereby keeping a quasi-constant working distance without the need of an external electronic feedback system like in AFM measurements and can even provide images of surfaces too rough to be imaged by AFM. In contrast to shear-force approaches, no accumulation of the shear force signal is necessary and larger lateral scan rates become possible. Numerical simulations by the boundary element method (BEM) were performed in order to understand the distance-dependent signals of the soft stylus probes.

\section{EXPERIMENTAL SECTION}

Chemicals. $\mathrm{K}_{3}\left[\mathrm{IrCl}_{6}\right]$ ( $\geq 99.5 \%$, Sigma-Aldrich, Schnelldorf, Switzerland), ferrocene methanol $\left(\mathrm{FcCH}_{2} \mathrm{OH}, \geq 97 \%\right.$, SigmaAldrich), $\mathrm{KNO}_{3}$ ( $\geq 99 \%$, Buchs, Switzerland), $\mathrm{KCl}$ ( $\geq 99.5 \%$, Fluka), $\mathrm{K}_{3}\left[\mathrm{Fe}(\mathrm{CN})_{6}\right]$ ( $\geq 99 \%$, Merck, Dietikon, Switzerland) were used as received. Deionized water was produced by a Milli-Q plus 185 model from Millipore (Zug, Switzerland).

Soft Stylus Probe Fabrication. Microchannels were prepared into $100 \mu \mathrm{m}$ thick polyethylene terephthalate (Melinex, PET, Dupont, Wilmington, DE) by UV-photoablation through a metallic mask using a $193 \mathrm{~nm}$ ArF excimer laser beam (Lambda Physik, Göttingen, Germany, fluence $=0.2 \mathrm{~J}$, frequency $=50 \mathrm{~Hz}$ ) as reported before for lab on a chip applications. ${ }^{56,57}$ The width, depth, and length of the prepared microchannels were usually 40

(47) Baranski, A. S.; Diakowski, P. M. I. Solid State Electrochem. 2004, 8, 683692.

(48) Diakowski, P. M.; Ding, Z. Electrochem. Commun. 2007, 9, 2617-2621.

(49) Etienne, M.; Schulte, A.; Schuhmann, W. Electrochem. Commun. 2004, 6, 288-293.

(50) Ballesteros, K. B.; Schulte, A.; Calvo, E. J.; Koudelka-Hep, M.; Schuhmann, W. Electrochem. Commun. 2002, 4, 134-138.

(51) Alpuche-Aviles, M. A.; Wipf, D. O. Anal. Chem. 2001, 73, 4873-4881.

(52) Zhang, M.; Wittstock, G.; Shao, Y.; Girault, H. H. Anal. Chem. 2007, 79, 4833-4839.

(53) Zhang, M.; Becue, A.; Prudent, M.; Champod, C.; Girault, H. H. Chem. Commun. 2007, 3948-3950.

(54) Zhang, M.; Girault, H. H. Electrochem. Commun. 2007, 9, 1778-1782.

(55) Zhang, M.; Su, B.; Cortes-Salazar, F.; Hojeij, M.; Girault, H. H. Electrochem. Commun. 2008, 10, 714-718.

(56) Roberts, M. A.; Rossier, J. S.; Bercier, P.; Girault, H. Anal. Chem. 1997, 69, 2035-2042. 


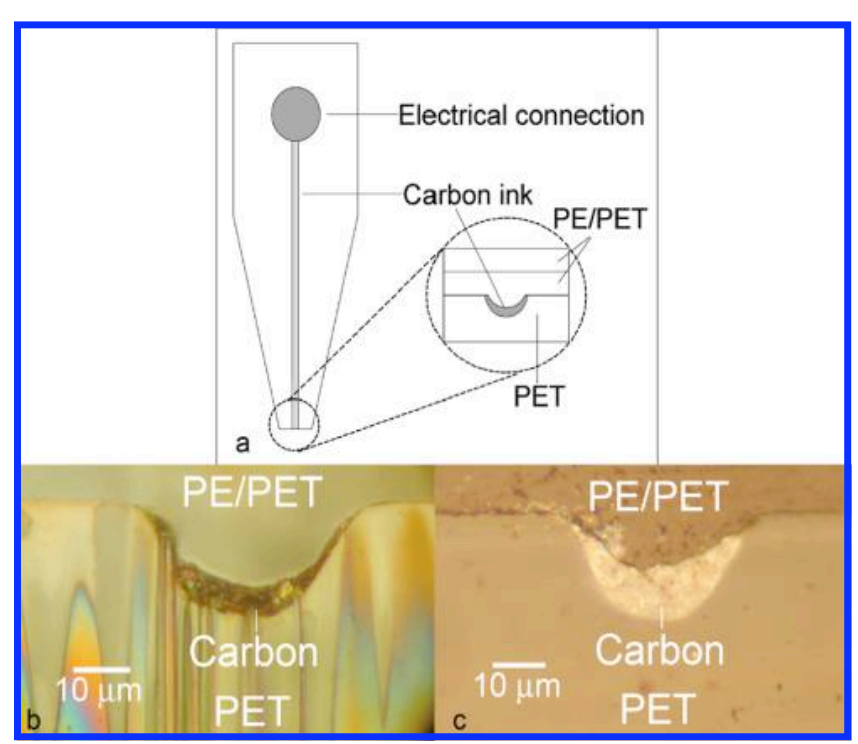

Figure 1. (a) Schematic representation of the soft stylus probe used as working electrode for SECM. (b) Optical image of the carbon electrode exposed by laser ablation (thickness $=6 \mu \mathrm{m}$, width $=32$ $\mu \mathrm{m})$. (c) Optical image of the carbon electrode exposed by mechanical polishing (thickness $=10 \mu \mathrm{m}$, width $=30 \mu \mathrm{m}$ ).

$\mu \mathrm{m}, 20 \mu \mathrm{m}$, and $5 \mathrm{~cm}$, respectively. Carbon ink (Electrador carbon ink, Electra Polymer and Chemicals Ltd., Roughway Mill, Dunk Green, England) was manually applied into the microchannels to create a carbon ink track and was subsequently cured at $80{ }^{\circ} \mathrm{C}$ for $1 \mathrm{~h}$. Then, two polyethylene/polyethylene terephthalate (PE/ PET, Payne, Wildmere Road, Banbury, England) lamination foils were applied over the electrode, not only to cover and seal it but also to adjust the mechanical rigidity. The soft stylus probe was then cut manually in a $\mathrm{V}$ shape such that the width of the probe at the end was about $0.5-1 \mathrm{~mm}$ (Figure 1a). The rigidity of the stylus depends on the tapering used during the cutting process. A cross section of the carbon track was then exposed either by laser ablation or by mechanical cutting and polishing by a succession of diamond lapping discs (Ultra-prep, Buehler, Schlieren, Switzerland) with different particle sizes (30, 6, and $0.1 \mu \mathrm{m})$. Sheet resistance measurements were performed using a collinear four-point probe with $1 \mathrm{~mm}$ separation between points (Jandel Engineering Ltd., U.K.).

Preparation of Gold Films. Glass slides were treated with Piranha solution and cleaned by sequential sonication in ethanol, acetone, and purified water followed by drying under a stream of Argon. Caution: This mixture reacts violently with all organic material. Piranha solution has to be handled with extreme care to avoid personnel injury and property damage. Gold films, $100 \mathrm{~nm}$ thick, were prepared in an Edwards Auto 306 evaporator operating at a pressure less than $5 \times 10^{-6} \mathrm{mbar}$. The film growth was initiated by thermal evaporation of a $1 \mathrm{~nm}$ thick chromium (99.99\%, Balzers) layer at $<0.1 \mathrm{~nm} / \mathrm{s}$ in order to enhance the adhesion of the Au layer. Gold (99.99\%, Balzers) was subsequently evaporated at $<0.1 \mathrm{~nm} / \mathrm{s}$ up to $5 \mathrm{~nm}$, before increasing the deposition rate to $0.2-0.3 \mathrm{~nm} / \mathrm{s}$ for the deposition of a 100 nm layer.

Preparation of Carbon Band Electrode Patterns. Two different sets of carbon bands were prepared. The first one was

(57) Rossier, J. S.; Roberts, M. A.; Ferrigno, R.; Girault, H. H. Anal. Chem. 1999, $71,4294-4299$. composed of two screen printed carbon bands over a polyester film. These two bands separated by $100 \mu \mathrm{m}$ presented an average thickness and band width equal to 7.1 and $900 \mu \mathrm{m}$, respectively. Another two carbon bands were screen printed over a glass slide with an approximate band separation of $\sim 1500 \mu \mathrm{m}$. The average thickness and band width obtained in this case was 118 and 1900 $\mu \mathrm{m}$, respectively. Topography profiles of the prepared samples were taken with a contact profilometer (Tencor Alpha-step 500).

SECM Measurements and Simulation. SECM measurements were carried out using a custom-built SECM setup running under SECMx software ${ }^{58}$ and comprising an IVIUM compactstat (IVIUM Technologies, NL), operating in a classical three-electrode setup. Data analyses were carried out using MIRA software. ${ }^{59}$ The electrochemical cell comprises a silver wire as quasi-reference electrode (Ag-QRE), a platinum wire as counter electrode, and a soft stylus probe as working electrode. All potentials reported herein are with respect to the Ag-QRE. The Pt microelectrode was polished using alumina 1 and $0.05 \mu \mathrm{m}$ on Mastertex polishing cloths (Buehler). After polishing, the quality of the electrodes was checked with a Laborlux D optical microscope (Leitz, Germany). All the samples were mounted on the bottom of a flat cell and investigated at room temperature $\left(20 \pm 2{ }^{\circ} \mathrm{C}\right)$. The BEM simulations were performed on a Linux openSUSE 10.3 platform with a $2 \mathrm{GHz}$ Core(TM) 2 Duo CPU and $4 \mathrm{~GB}$ of RAM. The simulation of individual geometric configurations took $4 \mathrm{~min}$ for conducting substrates (4966 boundary elements) and $38 \mathrm{~min}$ for insulating samples (11493 boundary elements)

\section{RESULTS AND DISCUSSION}

A schematic representation of the soft stylus probe obtained by the method described above is shown in Figure 1a. Figure 1b shows an example of a carbon electrode exposed by laser ablation machining (thickness $=6 \mu \mathrm{m}$, width $=32 \mu \mathrm{m}$ ), and Figure 1c displays an example of a carbon electrode exposed by blade cutting and mechanical polishing (thickness $=10 \mu \mathrm{m}$, width $=$ $30 \mu \mathrm{m})$. These images show clearly that the carbon track shrinks during the curing process and the thickness of the electrode is smaller than the depth (i.e., $20 \mu \mathrm{m}$ ) of the microchannel used to define the track. The thickness of the carbon electrode depends on the microchannel filling process, which is carried out manually and therefore is poorly controlled. In order to fabricate more reproducible electrodes, automated screen-printing techniques should be used. However, it is important to realize that the lamination method can accommodate the recess created over the cured ink track.

The soft stylus probes have been first characterized in an unbent state and immersed in the solution bulk, by approaching substrates with the active probe area parallel to the sample surfaces and, finally, in a contact mode, i.e., with a bent probe pressing as a flexible stylus on the substrate (Figure $2 \mathrm{a}-\mathrm{c}$ ).

Voltammetric Characterization. Cyclic voltammetry in 2.0 $\mathrm{mM} \mathrm{FeCH} \mathrm{CH}_{2} \mathrm{OH}$ was used to characterize the electrochemical behavior in bulk solutions as depicted in Figure 2a. A sigmoidal response is obtained, indicative of hemispherical diffusion together

(58) Nunes, K. C.; Hallmeier, K. H.; Szargan, R.; Raschke, T.; Radehaus, C.; Wittstock, G. Electroanalysis 2007, 19, 1023-1031.

(59) Wittstock, G.; Asmus, T.; Wilhelm, T. Fresenius'J. Anal. Chem. 2000, 367, 346-351. 


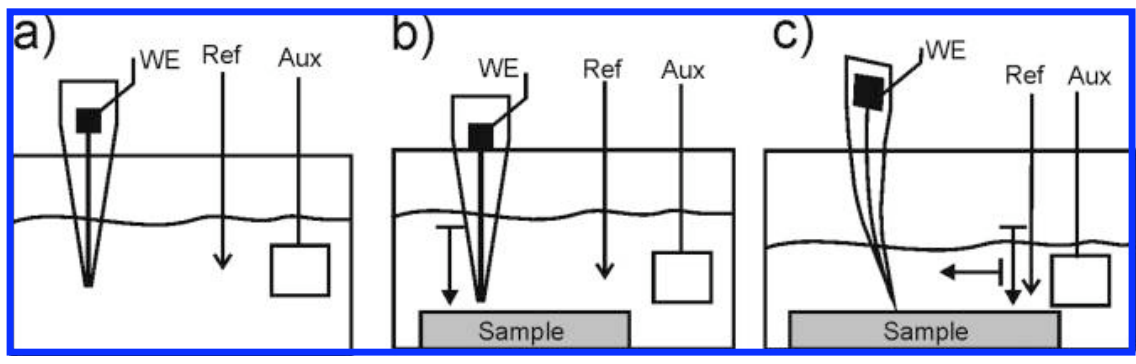

Figure 2. Operation mode of the soft stylus probes: (a) characterization in the solution bulk, (b) approach curves of unbent probes, and (c) approach curves and horizontal scans of bent probes.

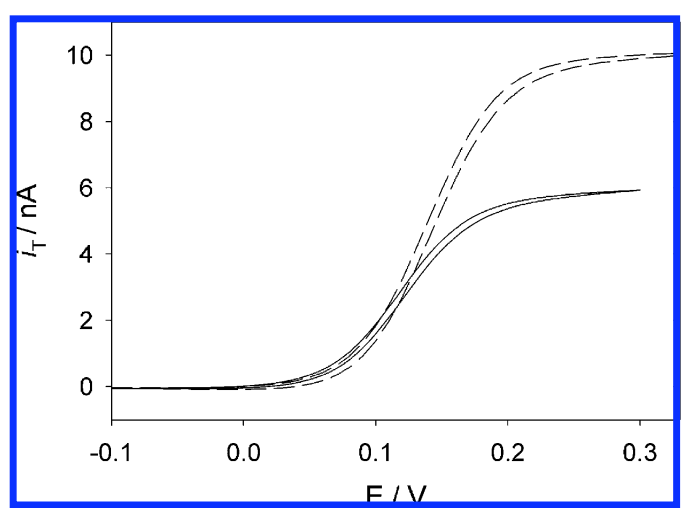

Figure 3. Cyclic voltammetry at soft stylus probes exposed by laser ablation (continuous line) and mechanical polishing (dashed line) in $2.0 \mathrm{mM} \mathrm{FcCH} \mathrm{mH}_{2} \mathrm{OH}$ and $0.1 \mathrm{M} \mathrm{KNO}_{3}$. Scan rate $=10 \mathrm{mV} / \mathrm{s}$.

with low charging current as a consequence of good sealing between the carbon track and the covering polymer layer (Figure 3). The difference of the steady-state currents of individual probes in Figure 3 reflects the different geometric areas of individual probes that can vary by $\sim 40 \%$. In order to compare the quality of the exposed electrode area, a wave-slope analysis of the cyclic voltammograms (CV) in Figure 3 was performed by plotting the applied electrode potential $E_{\mathrm{T}}$ as a function of $\log \left[\left(i_{\mathrm{T}, \infty}-i_{\mathrm{T}}\right) / i_{\mathrm{T}}\right]$, where $i_{\mathrm{T}, \infty}$ represents the diffusion-limited current in the solution bulk and $i_{\mathrm{T}}$ is the current at given potential in the bulk solution. This analysis gave slope values of 61.4 and $62.0 \mathrm{mV}$ for the laser ablated and mechanically polished electrodes, respectively. The slightly better electrochemical behavior shown by the soft stylus probes exposed by laser ablation is a likely consequence of the laser activation of the carbon flakes of the cured ink, similar to findings of previous studies. ${ }^{60-63}$ The difference existing between the experimental slope values and the theoretical value $(59.1 \mathrm{mV})^{64}$ for a reversible system comes in part from the internal resistance along the carbon track. ${ }^{65}$ The sheet resistance of cured screen printed carbon ink, which represents the ratio between the electrical resistivity and the thickness of a film, was measured using a four point probe equal to $7.7 \Omega$. The resistance $(R)$ of the carbon track of width $w$ and length $l$ is then given by

$$
R=R_{\mathrm{s}} \frac{l}{w}
$$

With a length of $5 \mathrm{~cm}$ and a width of $30 \mu \mathrm{m}$, the resistance of the carbon track can be estimated to be around $12.8 \mathrm{k} \Omega$, which results in a small $i R$ drop of a few millivolts.
As expected, cyclic voltammetry at high scan rates $(500 \mathrm{mV} /$ $\mathrm{s}$, not shown) gave a peak-shaped response, typical of planar diffusion. ${ }^{1}$ The latter result confirms that a good seal is obtained between the carbon track and the PE-PET films after either laser ablation or mechanical polishing. Despite the UV-photoablation exposure approach yielded probes with a slightly better electrochemical response, polished probes were mainly used in the following experiments, as they are easier to fabricate.

Approach Curve Characterization. Approach curves as depicted in Figure $2 \mathrm{~b}-\mathrm{c}$ were performed in $2.0 \mathrm{mM} \mathrm{FcCH}_{2} \mathrm{OH}$ either over an insulating (glass) or a conductive (gold film) sample. Figure 4a shows representative experimental curves. In all the experiments, the soft stylus probe was held at $E_{\mathrm{T}}=0.3 \mathrm{~V}$ to oxidize $\mathrm{FcCH}_{2} \mathrm{OH}$ under diffusion-controlled conditions. An unbiased gold film was used to drive the diffusion-controlled reduction of $\mathrm{FcCH}_{2} \mathrm{OH}^{+}$. Positive and negative feedback curves were observed when the soft stylus probe was approached to the gold film and the insulating glass, respectively (Figure 4a). The substrate position was determined as the inflection point of the probe approach curves. At this point, the insulating part of the probe mechanically touches the surface, but the substrateelectrode distance $d$ still has a finite value. If the probe is pressed against the substrate, it bends. In this way after contact, $d$ does not vary linearly with the movement of the mechanical positioning system. For this reason, we shall define $h_{\mathrm{A}}$ as the height of the attachment point of the soft stylus probe with respect to the sample surface (Figure 4c), which varies linearly with the $z$ position of the positioning system. If $l_{\mathrm{T}}$ is the length of the probe in the unbent state, the substrate-electrode distance $d$ that is always positive differs from the quantity $h_{\mathrm{P}}=h_{\mathrm{A}}-l_{\mathrm{T}}$ that can assume negative values when the probe is pressed against the substrate. The situation is shown in Figure 4c. After contact, the polished front end of the probe forms an angle $\alpha$ to the sample surface that increases upon further bending of the probe. With a distance of $85 \mu \mathrm{m}$ between the center of the active electrode area and the outer edge of the probe, the difference $d-h_{\mathrm{P}}$ is $85 \mu \mathrm{m}$ $\sin (\alpha)$ (see also S1 in the Supporting Information). $d$ always remains positive if the soft stylus probes cannot penetrate the sample. At the inflection point of the curve shown in Figure 4a, the current $\left(i_{\mathrm{T}}\right)$ over gold is about $1.45 i_{\mathrm{T}, \infty}$ and over glass 0.47 $i_{\mathrm{T}, \infty}$ with $i_{\mathrm{T}, \infty}=10.1 \mathrm{nA}$. A photographic sequence (results not

(60) Sternitzke, K. D.; McCreery, R. L. Anal. Chem. 1990, 62, 1339-1344.

(61) Etienne, M.; Oni, J.; Schulte, A.; Hartwich, G.; Schuhmann, W. Electrochim. Acta 2005, 50, 5001-5008.

(62) Rossier, J. S.; Girault, H. H. Phys. Chem. Chem. Phys. 1999, 1, 3647-3652.

(63) Osborne, M. D.; Seddon, B. J.; Dryfe, R. A. W.; Lagger, G.; Loyall, U.; Schafer, H.; Girault, H. H. I. Electroanal. Chem. 1996, 417, 5-15.

(64) Zoski, C. G. Electroanalysis 2002, 14, 1041-1051. 


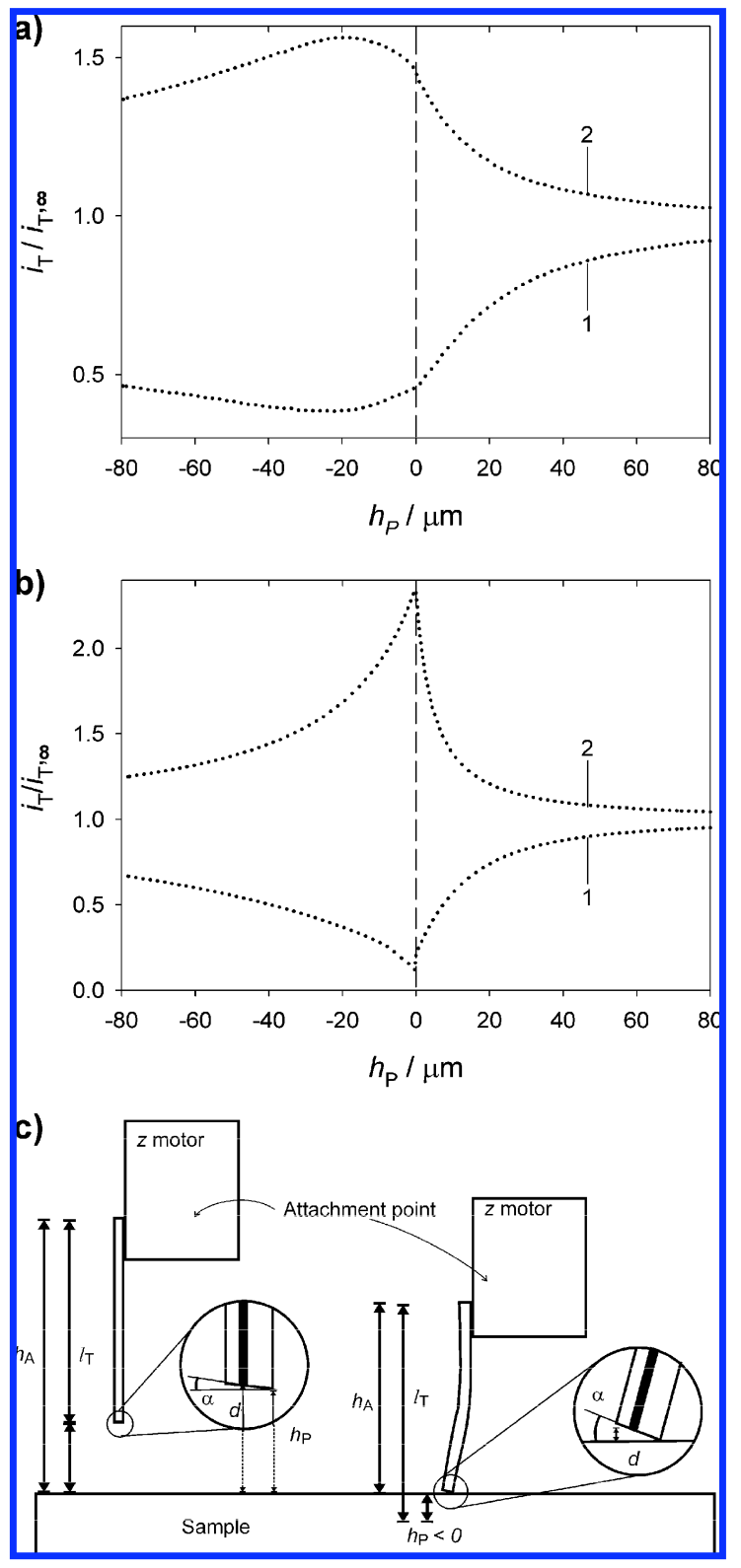

Figure 4. (a) Experimental approach curves with a polished soft stylus probe over insulating glass (1) and unbiased gold electrode (2). $E_{\mathrm{T}}=0.30 \mathrm{~V}$, translation rate $=0.5 \mu \mathrm{m} / \mathrm{s}$. (b) Simulated approach curve for a soft stylus probe, details in the Supporting Information. (c) Schematic representation of the SECM contact mode and the working distance for unbent and bent soft stylus probes.

shown) was taken in order to determine the probe tilt and contact angles $\alpha$ before and after the electrode contacted the substrate (due to the bending). According to this photographic sequence, the soft stylus probe was tilted about $3^{\circ}$ before touching the substrate. Therefore, at the probe-surface contact point corresponding to the inflection point in the approach curve, the distance $d$ is equal to $4.5 \mu \mathrm{m}$. For small negative values of $h_{\mathrm{p}}$, the current continues slightly to increase in positive feedback and decrease in negative feedback as the probe is squashed against the substrate before a clear bending mode is established.

The electrode geometry produced by the present methodology is close to a crescent moon shape. As a consequence, quantitative analyses are difficult since no analytical approximations are available for the description of the $i_{\mathrm{T}}-d$ relationship of such probes in SECM feedback experiments. We have used BEM simulations that are particularly useful to carry out threedimensional simulation of unsymmetric, steady-state problems. ${ }^{29,66-69}$ The electrode geometry for the simulation was taken from microphotographs and slightly idealized. The angle of the polished end of the soft stylus probe $(480 \times 200 \mu \mathrm{m})$ and the surface of the sample was assumed to be $3^{\circ}$. A sample surface of $1600 \times 1600 \mu \mathrm{m}$ was used. Together, this geometry is represented by 4966 triangles for simulations with conducting samples and 11493 triangles for simulations with insulating samples. Detailed representations of the meshes used are provided as Supporting Information (S1). The simulated approach curves are shown in Figure $4 \mathrm{~b}$. The extends of hindered diffusion is well described by the simulation. However, it shows that, in the contact mode, the current does not change too much if protruding insulating areas are encountered on the sample. For the positive feedback, the agreement for the unbent probe is also very high. However, for slightly bent probes, the theory predicts normalized feedback currents $I_{\mathrm{T}}=i_{\mathrm{T}} / i_{\mathrm{T} \infty}=2.2$, whereas currents of $I_{\mathrm{T}}=$ 1.5 were found experimentally. It could be expected that this current difference originated from a decrease of the local potential at the sharp crescent ends of the electrode, due to a higher ohmic drop produced by the higher current density at this zone. However, no current changes were observed when different supporting electrolyte concentrations (i.e., in the range from 0.05 to $0.2 \mathrm{M}$ ) were used in the different experiments. Additionally, in the experimental curves, the positive feedback increases after the touching point and hindered diffusion becomes more effective. This is most likely due to an elastic deformation at the end of the soft probes that decreases $d$. No deformation of the probe has been considered in the BEM simulation.

Contact Mode Scanning over Flat Surfaces. Figure 5 shows a series of line scans in a solution of $2.0 \mathrm{mM} \mathrm{FcCH}_{2} \mathrm{OH}$ as mediator over a glass-gold boundary with the probe either moving freely above the substrate as in a classical SECM measurement (lines 1 and $2, h_{\mathrm{p}}>0$ ) or pressed against the substrate in a bent contact mode (lines $\left.3-6, h_{\mathrm{p}} \leq 0\right)$ ). The scans were performed at scanning speeds of 10 or $20 \mu \mathrm{m} / \mathrm{s}$. A classical behavior is observed in the contactless mode with a negative feedback effect over the glass and a positive feedback over the unbiased gold (see S2 in the Supporting Information for a comparison with a disk shape UME). As soon as the probe touches the substrate (line $3, h_{\mathrm{p}}=0$ ), both the current over the glass and over the metal reach their minimum and maximum values, respectively. As can be seen, as the value $h_{\mathrm{p}}$ becomes more negative, the bending of the probe causes a shift of the horizontal registration $x_{\mathrm{R}}$ that is plotted as an inset.

Figure 5b shows a series of line scans performed in the bent contact mode and the corresponding SECM image of a partially

(65) Seddon, B. J.; Osborne, M. D.; Lagger, G.; Dryfe, R. A. W.; Loyall, U.; Schafer, H.; Girault, H. H. Electrochim. Acta 1997, 42, 1883-1894.

(66) Sklyar, O.; Trauble, M.; Zhao, C.; Wittstock, G. I. Phys. Chem. B 2006, 110, 15869-15877.

(67) Sklyar, O.; Treutler, T. H.; Vlachopoulos, N.; Wittstock, G. Surf. Sci. 2005, 597, 181-195.

(68) Sklyar, O.; Wittstock, G. I. Phys. Chem. B 2002, 106, 7499-7508.

(69) Holder, M. N.; Gardner, C. E.; Macpherson, J. V.; Unwin, P. R. L. Electroanal. Chem. 2005, 585, 8-18. 


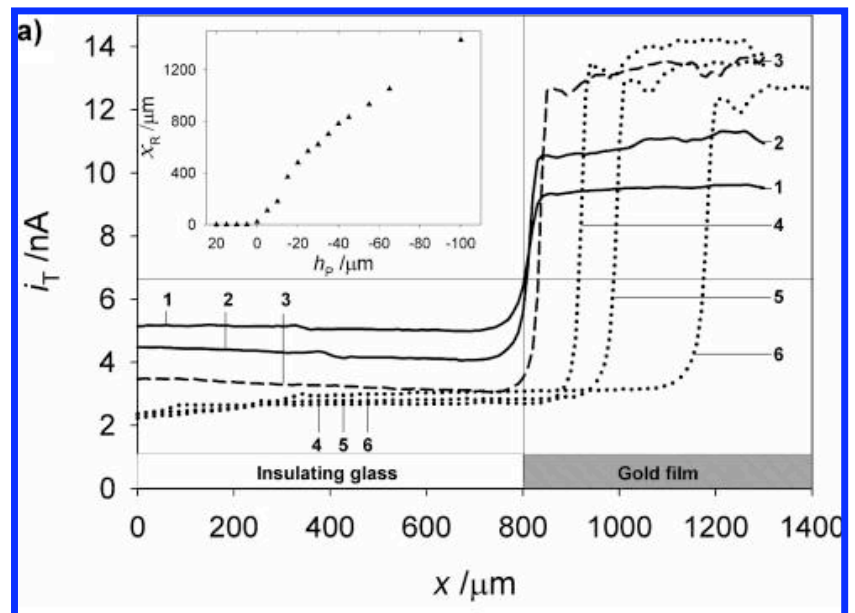

b)

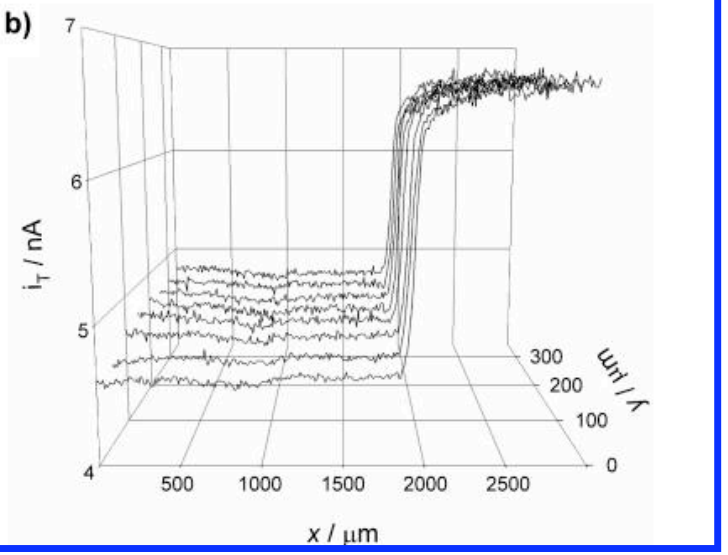

Figure 5. (a) Lateral SECM line scans in feedback mode with a soft stylus probe prepared by laser ablation over a glass partially covered by gold in $2.0 \mathrm{mM} \mathrm{FCCH}_{2} \mathrm{OH}$ and $0.1 \mathrm{M} \mathrm{KNO}_{3}$. $i_{\mathrm{T}, \infty}=6.65$ $\mathrm{nA}$ and the gold film position $(x=820 \mu \mathrm{m})$ are shown by thin solid lines; $E_{\mathrm{T}}=0.25 \mathrm{~V}$, step size $=20 \mu \mathrm{m}$, and translation rate $v_{\mathrm{T}}=20$ $\mu \mathrm{m} / \mathrm{s}$. Designation of the lines: (1) contactless $h_{\mathrm{P}}=20 \mu \mathrm{m}$; (2) contactless $h_{\mathrm{P}}=5 \mu \mathrm{m}$; (3)-(6) contact mode with the following probe positions $h_{\mathrm{P}}=0 \mu \mathrm{m}$ (3); $-5 \mu \mathrm{m}$ (4); $-10 \mu \mathrm{m}$ (5), and $-15 \mu \mathrm{m}$ (6). Inset: registration shift $x_{R}$ as a function of $h_{\mathrm{P}}$. (b) SECM image in contact mode of a partially gold-covered glass obtained using a soft stylus probe prepared by mechanical polishing. Imaging conditions: working solution $2.1 \mathrm{mM} \mathrm{FcCH}_{2} \mathrm{OH}, 0.1 \mathrm{M} \mathrm{KNO}_{3}, h_{\mathrm{P}}=-75 \mu \mathrm{m}, E_{\mathrm{T}}$ $=0.3 \mathrm{~V}$, step size in $x$ and $y$ direction was 10 and $50 \mu \mathrm{m}$, respectively. Translation rate $v_{T}=10 \mu \mathrm{m} / \mathrm{s}$. The substrate was tilted about $10 \mu \mathrm{m}$ along the $x$-axis.

gold-covered glass slide. Between each scan, the probe was lifted off the sample and returned to the original horizontal position where it was pressed against the substrate to the same bending degree $\left(h_{\mathrm{P}}=-75 \mu \mathrm{m}\right)$. This procedure was repeated several times to cover an area of $350 \mu \mathrm{m} \times 3000 \mu \mathrm{m}$. The sharp boundary line obtained shows that the registration shift remains constant for the different scans. Although the sample was tilted with a difference in height of $10 \mu \mathrm{m}$ over the scan length of $3000 \mu \mathrm{m}$, the current recorded is constant over the different areas. This clearly illustrates the advantages of a soft stylus probe approach to image the reactivity of surfaces with topographic artifacts. In fact, samples with a tilt height up to $90 \mu \mathrm{m}$ along a distance of $2000 \mu \mathrm{m}$ can be scanned without any problem (see S3 in the Supporting Information).
In order to determine the influence of the probe bending on the image resolution, we have calculated the parameter given by eq 2 , as reported previously: ${ }^{70}$

$$
\Delta x=\frac{\Delta i_{\mathrm{T}}}{\left(\frac{\partial i_{\mathrm{T}}}{\partial x}\right)_{x=x_{\text {inflection }}}}
$$

$\Delta x$ represents the required lateral distance to fully differentiate a conducting from an insulating area, while $\Delta i_{\mathrm{T}}$ is the difference between the probe currents above pure conducting and insulating materials. The gradient $\partial i_{\mathrm{T}} / \partial x$ is obtained by numerical differentiation of a line scan (see S4 in the Supporting Information), and it reaches a maximum over the boundary line. The $\Delta x$ values obtained for an average of eight line scans at $h_{\mathrm{P}}=$ $-5 \mu \mathrm{m}$ (not shown) and $h_{\mathrm{P}}=-75 \mu \mathrm{m}$ (shown in Figure $5 \mathrm{~b}$ ) were 49 and $64 \mu \mathrm{m}$, respectively. A similar analysis performed in contactless mode $(d=10 \mu \mathrm{m})$ under otherwise identical conditions produced a value of $\Delta x=32 \mu \mathrm{m}$. This difference may result from an increase of the electrode-substrate distance $d$ (the longer this distance, the poorer the resolution) and also from the asymmetry of the diffusion field in the contact mode compared to the contactless measurements. Indeed, simulations made for inclined AFM-SECM probes have shown similar results, where the tilted surface creates a shielding effect on the redox mediator diffusion. ${ }^{71}$ Nevertheless, Davoodi et al. showed that there are several advantages for SECM imaging with inclined probes, especially for the mapping of neighboring active sites. ${ }^{71}$

A long-term goal of this work is to image large areas ( $\sim$ centimeters squared), as, for example, complete human fingerprints. Within this scope, a minimum distance in the range of $\sim 50 \mu \mathrm{m}$ for fully differentiating one active region from a nonactive one is acceptable. However, there is room for improving the resolution of the images by producing probes with smaller track cross sections and thinner PET covers to decrease the working distance. For that, not only the active area but also the $R G$ value is important, since the latter does determine not only the diffusional shielding but also the working distance between the active electrode area of the probe and the sample. Both features have an impact on the resolution and can also be controlled by variation of the polishing process.

Contact Mode Scanning over 3D Patterns. The imaging of rough surfaces by SECM in the contact mode was also studied. This is important since other scanning probe techniques, like AFM and AFM-SECM, cannot scan surfaces with topographical differences higher than $\sim 10 \mu \mathrm{m}$ and are also limited in the lateral range. To assess the ability of the soft stylus probe for this kind of application, several line scans over screen-printed carbon bands separated by 100 or $1500 \mu \mathrm{m}$ and presenting thicknesses of $7 \mu \mathrm{m}$ (Figure 6a) or $118 \mu \mathrm{m}$ (Figure 6b), respectively,were performed. Figure 6a shows the line scans in contactless (line 1) and contact mode (line 2) after compensation of the registration shift. Both modes yield the same band width, which is larger than that obtained with a profilometer (see scheme at the bottom of Figure $6 a)$. In addition, when working in contact mode a decrease on the current contrast is produced due to the higher $d$ achieved.

Figure $6 \mathrm{~b}$ shows line scans in contact mode over the thick carbon electrodes $(118 \mu \mathrm{m}$ thick, see scheme at the bottom of 


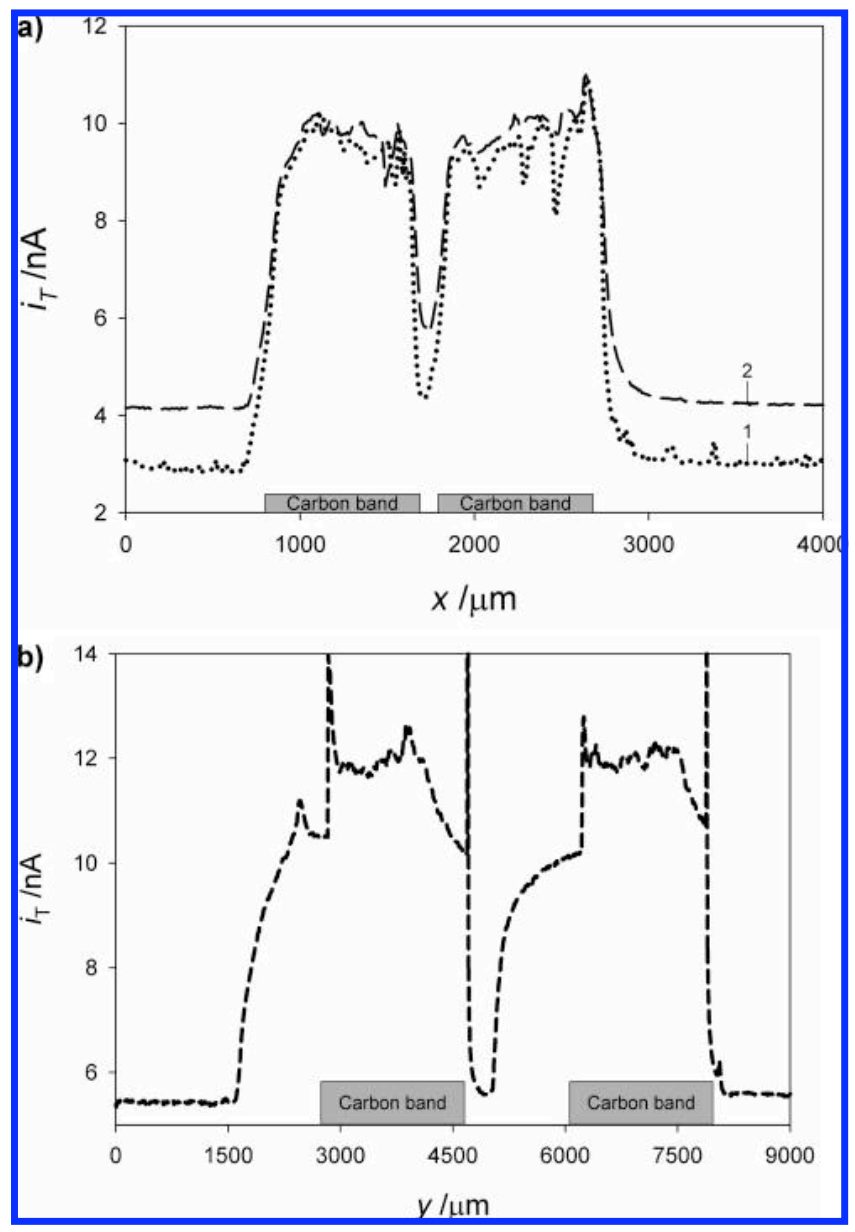

Figure 6. Lateral SECM line scans in feedback mode above a pair of unbiased carbon bands separated by a gap of $100 \mu \mathrm{m}$ (a) or 1500 $\mu \mathrm{m}$ (b), with a height above the surrounding matrix of $7.1 \mu \mathrm{m}$ (a) or $118 \mu \mathrm{m}$ (b), with a polished soft stylus probe in contactless (dotted line (a)) and contact mode (dashed lines (a) and (b)). A scheme of the topography profile obtained with a contact profilometer in air is presented at the bottom of each figure. SECM conditions: $h_{\mathrm{P}}=-75$ $\mu \mathrm{m}(\mathrm{a})$ or $-60 \mu \mathrm{m}(\mathrm{b}), E_{\mathrm{T}}=0.3 \mathrm{~V}$, step size $=10 \mu \mathrm{m}$, translation rate $v_{\mathrm{T}}=10 \mu \mathrm{m} / \mathrm{s}$, working solution $0.1 \mathrm{M} \mathrm{KNO}_{3}$ and $2.1 \mathrm{mM}$ $\mathrm{FcCH}_{2} \mathrm{OH}$ (a) or $2.4 \mathrm{mM} \mathrm{FcCH}_{2} \mathrm{OH}$ (b).

Figure $6 \mathrm{~b})$. It has to be realized that the contactless mode cannot be used over patterns with such a large aspect ratio without a feedback distance regulation system. Before starting the SECM line scans in contact mode, the probe was approached to the insulating glass until the desired value of $h_{\mathrm{P}}$ was reached. Once the scan was initiated, low current values were observed due to the blocking effect of the redox mediator diffusion over the glass substrate. Afterward, a current increase was observed as the probe got closer to (but not over) the first carbon band. This is a consequence of the physical contact that is established between the carbon band edge and the probe, lifting it off from the insulating substrate and leading to a current increase associated both to a lowering of the negative feedback process and perhaps to positive feedback with the edge of the carbon track. At the edge of the carbon electrode, it is interesting that a current peak can be observed as the probe passes over the boundary. Indeed, at that point, both the top surface and the edge contribute to the positive feedback. As the probe approaches the end of the substrate, the positive feedback current decreases slowly and then another sharp transition occurs

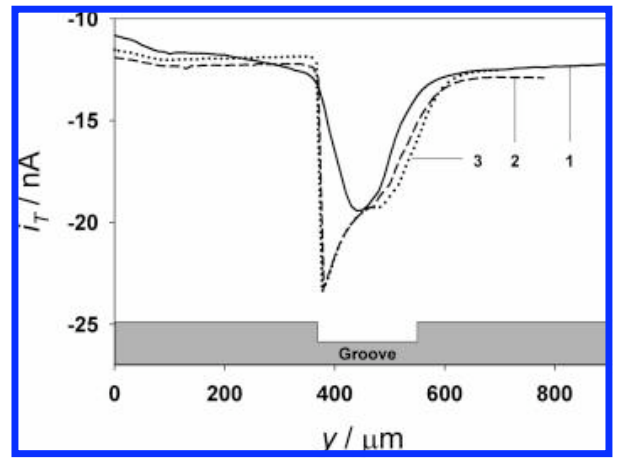

Figure 7. Horizontal SECM line scans in feedback mode over a PET film with an open microchannel (150 $\mu \mathrm{m}$ width) in $1.9 \mathrm{mM} \mathrm{K}_{3}\left[\mathrm{Fe}(\mathrm{CN})_{6}\right]$ and $0.2 \mathrm{M} \mathrm{KCl}$. The microchannel position is shown by the scheme at the bottom of the figure. Scanning conditions: (1) $h_{\mathrm{P}}=5 \mu \mathrm{m}$ (continuous line), (2) $h_{\mathrm{P}}=-1 \mu \mathrm{m}$ (dashed line), and (3) $h_{\mathrm{P}}=-10$ $\mu \mathrm{m}$ (dotted line). $E_{\mathrm{T}}=-0.1 \mathrm{~V}$, step size $=50 \mu \mathrm{m}$, translation rate $v_{\mathrm{T}}$ $=50 \mu \mathrm{m} / \mathrm{s}$.

when the probe jumps to the substrate level. It is likely that electrical contacts between the carbon bands on the sample and the carbon track of the probe are established at $y=4600$ $\mu \mathrm{m}$ and $y=8000 \mu \mathrm{m}$. This is concluded from the very sharp decrease of the current upon minimal lateral offset of the sample (compare the decay of the peaks at $y=4600 \mu \mathrm{m}$ with that at $y=2700 \mu \mathrm{m})$. Nevertheless, Figure $6 \mathrm{~b}$ illustrates the major advantage of the soft stylus probe over the classical SECM probe that cannot provide any information for surfaces with such aspect ratios.

Finally, a groove (150 $\mu \mathrm{m}$ width, $40 \mu \mathrm{m}$ depth) fabricated into a PET substrate was topographically characterized using a soft stylus probe exposed by mechanical polishing and $\left[\mathrm{Fe}(\mathrm{CN})_{6}\right]^{3-}$ as mediator. Figure 7 shows horizontal line scans at different $h_{\mathrm{P}}$ values after correction of the registration shift. Line scans performed in contactless (line $1, h_{\mathrm{P}}=5 \mu \mathrm{m}$ ) and contact modes (lines 2 and $3, h_{\mathrm{P}}=-1$ and $-10 \mu \mathrm{m}$ ) show higher cathodic currents when the soft stylus probe was over the microchannel due to the less effective shielding of the mediator diffusion. In contact mode, the first groove edge causes an abrupt change of current as the probe snaps into the channel with an undepleted mediator concentration. At the other side of the channel, the stylus probe is gradually more bent and only after some distance from the groove rim the same hindered diffusion is observed, as just before entering the channel.

The slowly rising current before the high carbon band and the slowly decreasing current after the groove should produce images with a shadow as in photography with an object illumination coming at an angle.

\section{CONCLUSIONS}

The results presented above show that classical microfabrication methods can be used to produce soft stylus probes for SECM that can operate in contactless and more especially in contact mode over large tilted substrates with patterns of high aspect ratios. This contact mode has been developed to scan large areas

(70) Wittstock, G.; Emons, H.; Ridgway, T. H.; Blubaugh, E. A.; Heineman, W. R. Anal. Chim. Acta 1994, 298, 285-302.

(71) Davoodi, A.; Farzadi, A.; Pan, J.; Leygraf, C.; Zhu, Y. L. Electrochem. Soc. 2008, 155, C474-C485. 
such as electrophoresis gels, fingerprints, or libraries for material testing to avoid problems with sample tilt and limited translation rates in constant distance mode with an electronic distance regulation. Soft stylus probes are very stable and can be used many times, since the electrode surface can be regenerated by gentle polishing. In addition, probe stiffness can be tuned (e.g., by adjusting the overall width and tapering of the probe) to prevent the probe from penetrating the sample. By extension of the imaging software routines, we plan to automatically image surfaces of high roughness, such as the samples used in Figures 6 and 7.

\section{ACKNOWLEDGMENT}

The Fonds National Suisse pour la Recherche Scientifique (Grant No. 20PA21_121570/1 "High throughput SECM imaging") and Deutsche Forschungsgemeinschaft (Wi 1617/10) are thanked for financial support. We are grateful to Michel Prudent and
Manuel Alejandro Mendez (EPFL, LEPA) for their helpful discussions. The technical assistance by Valérie Devaud is also acknowledged.

\section{SUPPORTING INFORMATION AVAILABLE}

Details of the BEM simulation, as well as, comparative SECM images of conductive and insulating substrates obtained with both a common UME and a soft stylus probe in contactless mode, line scans over tilted surfaces, and the numerical differentiation of a lateral SECM line scan. This material is available free of charge via the Internet at http://pubs.acs.org.

Received for review April 24, 2009. Accepted June 18, 2009.

AC900887U 